\title{
A novel endoscopic submucosal dissection training model using skinned chicken meat with gel
}

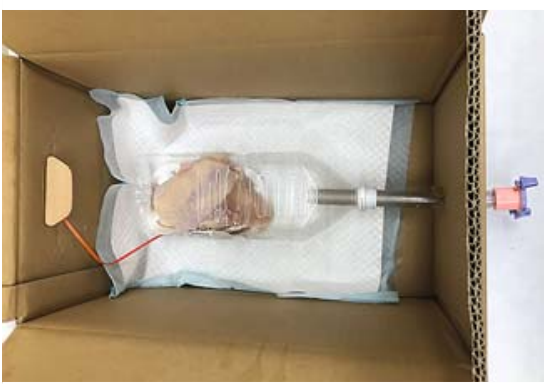

- Fig. 1 Setting the skinned chicken meat with an electrode in a 2-L polyethylene terephthalate bottle.

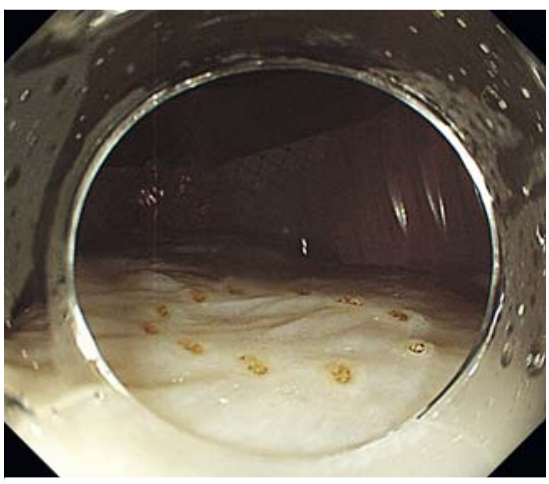

- Fig. 2 Endoscopic image showing circular markings on the chicken skin.

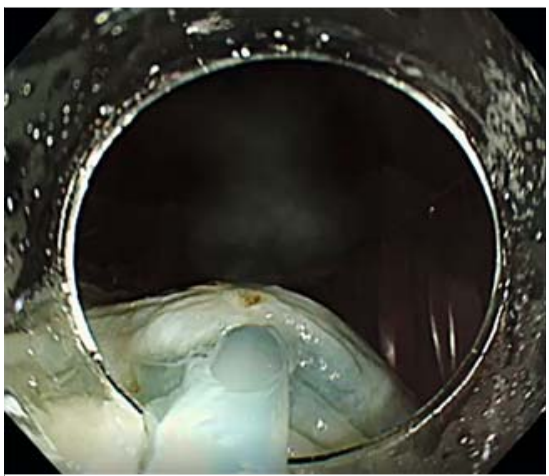

- Fig. 3 Endoscopic image showing lifting of the chicken skin by injections of two solutions and creating a gel layer.

Gastric endoscopic submucosal dissection (G-ESD) is performed worldwide. However, some trainees are not of-
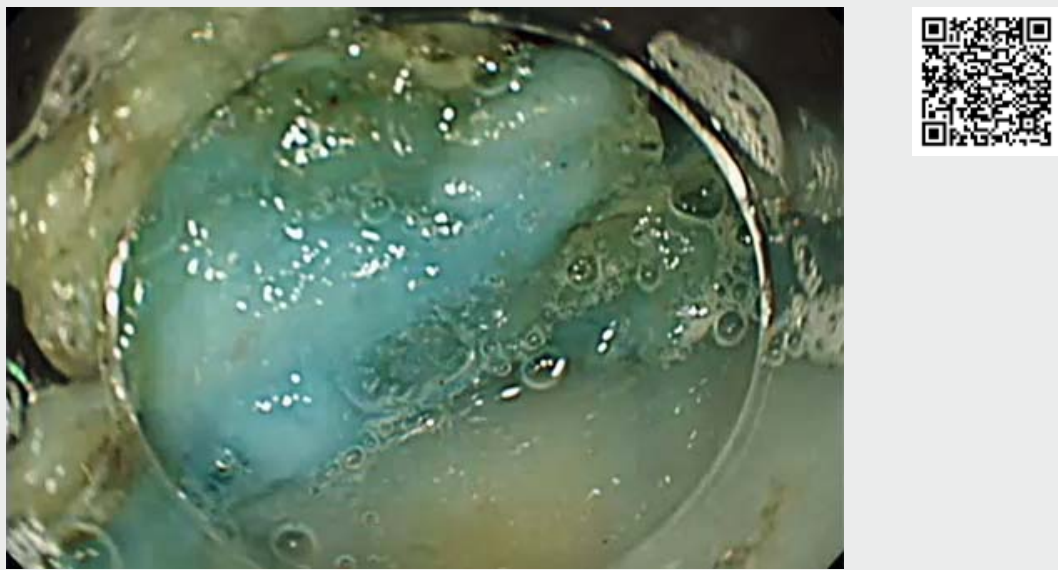

$\checkmark$ Video 1 Endoscopic submucosal dissection training model using chicken meat with gel.

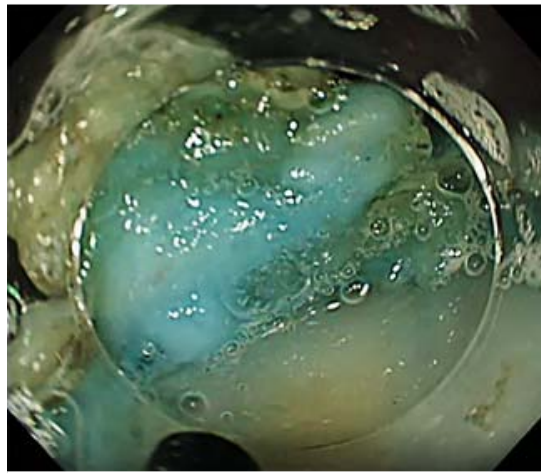

- Fig. 4 Endoscopic image showing a dissection view of the gel layer.

fered sufficient opportunities to perform G-ESD. Therefore, hands-on seminars using porcine stomachs are actively held, serving as valuable learning opportunities for trainees [1]. However, preparing porcine stomachs is time-consuming and effort-intensive, and leads to problems related to sanitation and pollution. To address these issues, we developed a new G-ESD training model using skinned chicken meat with gel involving the following steps ( $\triangleright$ Video 1). (1) An electrode is attached to the chicken meat on

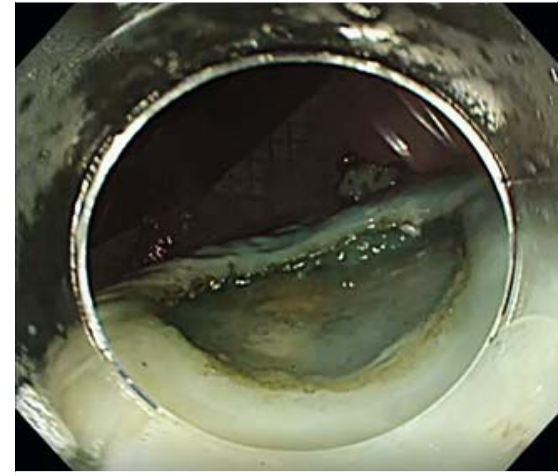

Fig. 5 Chicken skin after resection.

the skinless slide ( $\triangleright$ Fig. 1). (2) The chicken meat is placed in a $2-\mathrm{L}$ polyethylene terephthalate bottle (\$ Fig.1). (3) Circular marks are made to mimic a virtual tumor region (> Fig. 2). (4) The first injection solution is made by mixing $40 \mathrm{~mL}$ of clear-type polyvinyl alcohol glue with $30 \mathrm{~mL}$ of water. The second injection solution is made by dissolving $3 \mathrm{~g}$ of borax in $50 \mathrm{~mL}$ of warm water and adding $3 \mathrm{~g}$ of sodium hydrogen carbonate. These two solutions are injected subcutaneously, and skin lifting is observed, similarly to that of the gastric mucosa ( $>$ Fig. 3). (5) 
The skin is cut using a knife, and the cut is gradually widened ( $>$ Fig.4, $\triangleright$ Fig. 5 ). The two liquids are mixed and injected under the chicken skin (to mimic the submucosal layer). The greatest advantages of this model are that i) skinned chicken meat can be purchased from any supermarket, ii) there is a low infection risk for hepatitis $E$ virus or other zoonotic infections, and iii) it is a low-cost model (\$1.50-1.70). Chicken meat preparation is fast, simple, and inexpensive compared with porcine model preparation. Therefore, G-ESD training using this novel model is feasible, efficient, and may be widely available for trainees who do not have the chance to practice G-ESD or attend hands-on seminars.

Endoscopy_UCTN_Code_TTT_1AU_2AB

\section{Competing interests}

The authors declare that they have no conflict of interest.
The authors

Sho Suzuki, Hiroshi Kawakami, Tadashi Miike, Yutaro Ishikawa, Tomoya Hirata, Naoki

\section{Ichinari, Anna Komura}

Department of Gastroenterology and Hepatology, Center for Digestive Disease and Division of Endoscopy, University of Miyazaki Hospital, Miyazaki, Japan

\section{Corresponding author}

\section{Hiroshi Kawakami, MD, PhD}

Department of Gastroenterology and Hepatology, Center for Digestive Disease, Division of Endoscopy, University of Miyazaki Hospital, 5200 Kihara, Kiyotake, Miyazaki 889-1692, Japan

Fax: +81-985-859802

hiropon@med.miyazaki-u.ac.jp

\section{Reference}

[1] Berr F, Ponchon T, Neureiter D et al. Experimental endoscopic submucosal dissection training in a porcine model: learning experience of skilled Western endoscopists. Dig Endosc 2011; 23: 281-289
Bibliography

Endoscopy 2021; 53: E334-E335

DOI 10.1055/a-1287-8567

ISSN 0013-726X

published online 3.11 .2020

(c) 2020. Thieme. All rights reserved.

Georg Thieme Verlag KG, Rüdigerstraße 14,

70469 Stuttgart, Germany

\section{ENDOSCOPY E-VIDEOS}

https://eref.thieme.de/e-videos

回回 Endoscopy E-Videos is a free

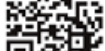
access online section, reporting 回然品 on interesting cases and new

techniques in gastroenterological endoscopy. All papers include a high quality video and all contributions are freely accessible online.

This section has its own submission website at https://mc.manuscriptcentral.com/e-videos 